University of Nebraska - Lincoln

DigitalCommons@University of Nebraska - Lincoln

To Improve the Academy

Professional and Organizational Development Network in Higher Education

1994

Reclaiming Teaching Excellence: Miami University's Teaching

Scholars Program

Milton D. Cox

Follow this and additional works at: https://digitalcommons.unl.edu/podimproveacad

Part of the Higher Education Administration Commons

Cox, Milton D., "Reclaiming Teaching Excellence: Miami University's Teaching Scholars Program" (1994). To Improve the Academy. 305.

https://digitalcommons.unl.edu/podimproveacad/305

This Article is brought to you for free and open access by the Professional and Organizational Development Network in Higher Education at DigitalCommons@University of Nebraska - Lincoln. It has been accepted for inclusion in To Improve the Academy by an authorized administrator of DigitalCommons@University of Nebraska - Lincoln. 


\section{Reclaiming Teaching Excellence: Miami University's Teaching Scholars Program}

\section{Milton D. Cox}

Miami University

The 1994 Hesburgh Award-winning Teaching Scholars Program for junior faculty at Miami University is described, implementation and program strategies are discussed, and the effectiveness and impact of the Program are assessed.

\section{Introduction}

The longest running junior faculty development program in the United States has received the 1994 Hesburgh Award, given by TIAA/CREF to the outstanding faculty development program that has improved undergraduate teaching. Established in 1978 by Miami University, the Teaching Scholars Program was developed to systematically reclaim the importance of teaching at the University. The Program focuses on junior faculty and assists their development of teaching abilities through participation in a two-semester series of special activities and individual projects related to teaching.

Over the last 20 years, the welfare of new and junior faculty in academe has been neglected. Research about their experiences, stresses, and strategies to improve their lot have appeared in many articles and reports during the past decade, as well as in books by Boice (1992) and Sorcinelli and Austin (1992). A more detailed look at 
Miami's Teaching Scholars Program, incorporating this literature, can be found in Cox (in press).

Founded in 1809, Miami University is a state-assisted, residential university in Oxford, Ohio. The Oxford campus enrollment is approximately 16,000 (including 14,000 undergraduates), with an additional 4,000 students on two nearby, nonresidential, urban two-year regional campuses. Miami University has a history and tradition of emphasis on undergraduate teaching. Its mission statement includes the following goals: "to provide an environment conducive to effective and inspired teaching and learning, and to promote professional development of faculty. .." During the 1950 s and 60 s, as enrollment tripled and doctoral programs were developed, Miami experienced a change in its academic culture similar to other campuses across the nation. This was a period of growing expectations for universities to play an important role in producing new knowledge to contribute to the betterment of society. Concern that this change in culture could negatively impact learning by undergraduates led to a concerted effort to study the problem and search for solutions. A committee of senior faculty, students, and administrators appointed by the Provost in 1978 proposed a solution. The result was the development of the Teaching Scholars Program, directed by a faculty member under the auspices of the University Senate's Committee on the Improvement of Instruction.

\section{Program Goals, Objectives, and Activities}

The objectives of the Miami Teaching Scholars Program have been to provide junior faculty with information on teaching and learning, observation of successful teaching, practice in using new skills and technology, time and support for individual investigations of teaching problems and projects, opportunities to share ideas and advice with senior faculty mentors, experience with the scholarship of teaching, and colleagueship across disciplines.

For the university, the long-term goals of the Program have been to increase faculty interest in undergraduate teaching and learning, inform faculty about teaching and active learning in the multicultural classroom, build university-wide community through teaching, in- 
crease faculty collaboration and the coherence of learning across disciplines, nourish the scholarship of teaching, and broaden the evaluation of and increase the rewards for teaching.

Full-time faculty in tenure-track positions are eligible to participate in the Program during their second through fifth years of teaching at Miami. Nine to 13 applicants are chosen in April for participation the next year. A joint call for applications, issued by the Provost and the Program Director, is mailed to all eligible faculty. The Provost also writes to chairs and deans, asking them to encourage their faculty to apply. A subcommittee of the Committee on the Improvement of Instruction reads the written applications and makes the selections. Criteria for selection include commitment to quality teaching, level of interest in the Program, need, potential for contributions to the Program, and plans for the award year. The selection committee works diligently to create gender balance and to create a diverse group across disciplines, campuses, and participants' needs and experiences.

During their year in the Program, the Teaching Scholars participate in a wide variety of activities.

Seminars on teaching and learning. The Teaching Scholars select seminar topics and speakers after consulting with the previous year's group and the Program Director. Often-selected topics include using discussion in the classroom, the effect of gender on the teaching and learning process, infusing cultural diversity across the curriculum, enhancing the teaching and learning experience through awareness of students' intellectual development, creating teaching portfolios, videotaping to enhance teaching effectiveness, ethical dilemmas in teaching, and the scholarship of teaching.

Senior faculty mentoring. Teaching Scholars select one or two senior members of the faculty to serve as their mentors. Over 125 Miami faculty have volunteered to serve as teaching resources, listing more than 50 areas of teaching expertise. From a pool including this list, former Teaching Scholars and Mentors, or interesting colleagues they have met, the new participants interview and select a Mentor in consultation with the Program Director and their department chair. The trend over the years has moved from selecting a mentor in one's department to choosing someone from a noncognate department. The structure of their interaction is flexible: For example, the mentors and 
proteges may attend one another's classes, discuss teaching philosophies, or explore university issues together.

Teaching projects. The Teaching Scholars pursue self-designed and peer-reviewed learning programs, including teaching projects, for which they receive financial support. Projects have included developing computer-assisted instruction, learning and trying classroom assessment techniques, redesigning a course to include the contributions of women, and surveying students and faculty about social and interpersonal aspects of teaching and learning.

Retreats. An opening/closing retreat is held in May so that graduating participants can share their mentoring, project, and seminar experiences with the new group. In October, another college campus, with a mission and students very different from those of Miami, is the setting for seminars with host faculty and students. In February, the participants lead teaching seminars at the campus-wide Miami Teaching Effectiveness Retreat.

National conferences. Each November, the Teaching Scholars participate in the annual Miami Lilly Conference on College Teaching, where they have the opportunity to meet and consult with nationally known teacher scholars. In March, members of the group present papers at a national teaching conference.

\section{Program Strategies}

Miami University utilized the following strategies in developing this program to improve teaching. Faculty developers at other colleges and universities may find many of these ideas helpful, depending upon the culture at their institutions.

- Make the keystone of teaching improvement efforts a year-long teaching program for junior faculty, as a long-term investment in the university, a "greening of the future" (at Miami, the Program's motto). As junior faculty become tenured and assume leadership in their departments, their high esteem for teaching and their positive experience with the university community will have a ripple effect throughout the institution. 
- Involve all citizens of the university - administrators, students, and faculty - in the workings of the program but place ownership with the faculty.

- Obtain secure funding and official faculty endorsement to sustain the program as a long-term endeavor.

- View an individual's participation in the program as an honor, a positive achievement, and an indication of strong interest in teaching.

- Select participants to create a cross-cultural balance in the program - across gender, disciplines, campuses, and participants' needs and previous teaching experiences.

- Provide junior faculty participants with release time from at least one course for at least one semester.

- Create opportunities for participants to broaden their perspective and understanding of teaching and learning beyond the home campus.

- Involve tenured faculty as mentors in a flexible way. Reward mentors with recognition, complimentary books on teaching, thank-you dinners, and the like. In a real sense, they are participants in the program and, in some cases, may grow as much as the junior faculty.

- Involve the junior faculty participants in the design and assessment of programming, including seminar topics, retreats, teaching projects, and mentoring.

- Illustrate, encourage, and provide outlets for the scholarship of teaching.

- Provide an opportunity for participants to share their interest in and enthusiasm for teaching with other faculty, thus expanding the impact of the program. For example, participants can lead a teaching retreat for faculty, with presentations featuring the results of teaching projects.

- Assess all program components and participant development, and use the feedback for planning, funding, and continuation of the program.

- Design activities, accommodations, and recognition to make participants feel valued and respected by the institution. 
- Communicate desired teaching and learning outcomes. The university president and the provost should be outspoken in their support of the program and its objectives; still, the participants are the best spokespersons, as they share their enthusiasm with other new faculty and their departmental colleagues via teaching retreats and mentoring.

Miami's Teaching Scholars Program addresses the challenge to the university community of reclaiming teaching and learning excellence by providing guidance and assistance to new faculty in their formative years in the professoriate. This challenge is part of the larger issue of the culture of the academy and the need to make the teaching and learning of undergraduates as important, respected, and valued as discovery research.

Miami's Teaching Scholars Program represented a fresh direction in faculty development programs in 1978. It retains that freshness today because of constant nurturing and improvement by a committed university administration, faculty, student body, and alumni. Thus, the current Program is comprehensive, incorporating several proven and innovative elements:

- Sixteen years ago, the strategy of involving senior faculty as mentors was bold, because it had failed on several campuses. However, because of Miami senior faculty's the dedication to teaching, the mentoring part of the Program continues to be successful. Some participants now select two mentors, one within and one outside their department.

- An important component is the engagement of participants with teaching and learning issues in different cultures (i.e., a retreat with faculty at a very different type of campus and attendance at the Lilly Conference on College Teaching-West in California).

- The emphasis on the scholarship of teaching, particularly the initiation of a national teaching conference and a refereed journal, encourages Program participants to see and present pedagogical scholarship.

- This year, several Teaching Scholars are experimenting with the teaching portfolio approach to the evaluation of teaching. 
- The most recent new direction is the establishment of Miami's Office for the Advancement of Scholarship and Teaching, in which the Program now is housed. The new office encourages faculty to find ways to link teaching and research in working with undergraduates.

- Funding of the Program by alumni is unique. It demonstrates a strong endorsement by former students.

- The university's long-term commitment to the Program is unusual. By 1984, most of the extensions of previous Lilly Teaching Fellows Programs at other universities had ended, yet Miami's strong commitment continues to the present.

\section{Success and Impact}

Over the past 16 years, the Teaching Scholars Program has had widespread influence. However, recent new emphases may extend further its impact on balancing the prestige and rewards for scholarship and teaching, broadening the evaluation of teaching and assessment of learning, enlarging common ground between university-wide missions and departmental cultures, increasing active learning in the classroom, enhancing learning in the multicultural classroom, and involving undergraduates in research.

The initial three years of the Program were funded by a Lilly Endowment Grant as part of the Lilly Teaching Fellows Program. When the University Senate overwhelmingly endorsed continuation of the Program after the third year, the Miami alumni assumed funding of the Program and continue to fund the Program today. Because of the value and success of the Program over the years, Miami's alumni have increased funding continually so that more extensive initiatives could be undertaken. These initiatives include a wide variety of teaching grants and leaves, the Lilly Conferences on College Teaching, the Journal on Excellence in College Teaching, the Senior Faculty Program for Teaching Excellence, and the Teaching Portfolio Project. All grants, awards, policy decisions, selection of participants, and budget recommendations are made by the faculty and students on the Committee on the Improvement of Instruction. This faculty and student commitment to teaching is a valuable resource. The half-time 
Program Director (a faculty member) and third-time secretary of the Program coordinate the process. Thus, most of the funds have been invested directly in faculty and their development, with only a small percentage used for administration.

The Teaching Scholars complete an annual evaluation that asks what impact their participation in the Program has had on them. They report that the greatest impact is on their interest in the teaching process. Over the past 12 years, the mean for "interest in the teaching process" has been 8.4 on a 10-point scale (with 10 the highest).

The scholarship of teaching (Boyer, 1990) has been nourished in a variety of ways. This scholarship is developed for the junior faculty participants gradually over the year through a sequence of steps: design and implementation of a teaching project; selection and use of classroom assessment techniques; reading of teaching literature; attendance at a national teaching conference, with opportunities to meet nationally known teacher-scholars; presentation of a teaching seminar on campus, followed by a presentation at a national teaching conference; and encouragement to prepare a manuscript for publication. Although the scholarship of teaching was not a buzzword when the Program was first developed, the outward focus of the Program participants was part of the movement that created high quality teaching scholarship. For example, Program seminars have been led by teacher-scholars working at the cutting edge of teaching and learning theory. Marcia Baxter Magolda, a Program participant in 1985-86, published the book, Knowing and Reasoning in College (1992), about the intellectual development of students. Blythe Clinchy and Mary Belenky (1986) gave presentations on the effect of gender in teaching and learning, while Tom Angelo and Pat Cross (1993) conducted seminars on classroom assessment techniques. Ernest Boyer and Gene Rice addressed participants on the new scholarship, and Barbara Millis (1991) worked with the group on cooperative learning. Bill McKeachie (1994) discussed faculty's teaching projects with participants, and Joe Lowman (1984) consulted with them about videotapes of their teaching. The participants rank the scholarship of teaching second of all elements of the Program (mean of 8.2 on the 10-point scale) in terms of impact on their teaching. 
Although progress began to be made in transforming the culture at Miami to one that values the scholarship of teaching, participants next recognized that the change was not national in scope. To have a lasting effect, there also would have to be a national change in academic culture. To help this happen, to provide an outlet for the participants' scholarship of teaching, and to involve participants in more diverse cultures, the Teaching Scholars Program undertook the following two important national initiatives.

The Lilly Conference on College Teaching. Since its inception in 1981, the Lilly Conference on College Teaching at Miami has grown from 50 participants to 400 . The 14th Annual Lilly Conference will be held in November 1994. Each conference now features over 30 nationally known presenters and 50 contributed papers. In addition, Miami University has, with various California institutions, developed and cosponsored the Lilly Conference on College Teaching-West, which will hold its 7th annual meeting in March 1995. In June 1995, the first Lilly Conference-South will be cosponsored with the University of South Carolina. Teaching Scholars Program participants present at these conferences, where both novice and expert teacher-scholars from a wide variety of campus cultures share their classroom experiences and teaching and learning innovations.

Journal on Excellence in College Teaching. With the support of Miami alumni donations and a national editorial board (mostly active Lilly Conference participants over the years), the Journal has published four annual volumes and moved to two issues for Volume 5 in 1994. Invited for submission are papers on college teaching that demonstrate excellence in one of these areas: research, integration, innovation, or inspiration. Featured articles have been written by Peter Beidler, Blythe Clinchy, K. Patricia Cross, Tony Grasha, Barbara Millis, John Roth, and other nationally known experts. The Journal is abstracted by ERIC and Higher Education Abstracts.

Teaching Scholar Program participants take advantage of the above opportunities. For example, Helaine Alessio, a Program participant in 1989-90, presented a paper on her teaching project, "Use of Educational Games for Difficult Subject Material," at the 1989 Lilly Conference. Her manuscript was reviewed by peers and published in the second volume of the Journal on Excellence in College Teaching 
(1991). Catherine Bishop-Clark and Jean Lynch, 1990-91 participants, presented the results of their teaching project, "The Mixed-Age Classroom," at the 1992 Lilly Conference and published the resulting article in the Summer 1992 issue of College Teaching. Barbara Flannery and Maureen Vanterpool, 1989-90 participants, presented at the 1990 Lilly Conference and published the results of their project, "Infusing Cultural Diversity Concepts Across the Curriculum," in the 1991 To Improve the Academy. Philip Cottell, 1985-86 participant, attended Barbara Millis's cooperative learning workshop at the 1985 Lilly Conference, became excited about cooperative learning, used it in his classes, joined POD, presented several joint workshops with Millis, and joined with Millis to coauthor an instructor's resource guide (Cottell \& Millis, 1994).

Awards for excellent teaching at Miami have increased. When the Program was established, there were only two teaching awards on campus. Now there are over 10 annual awards, given by divisions, departments, and regional consortia. Some awards carry attractive stipends.

Financial support for teaching has grown considerably. The success of the Program and the enthusiasm of its participants have generated a tenfold increase in the developmental support of teaching. Since 1978, the Miami alumni and the Provost have expanded the annual budget available to the Committee on the Improvement of Instruction from $\$ 15,000$ to over $\$ 150,000$. Resources now support small grants to improve teaching, teaching leaves (for mid-career faculty), faculty exchanges, department/program grants to encourage teaching initiatives by entire departments, visiting teacher-scholar grants, travel grants to attend teaching conferences, and new initiatives such as the teaching portfolio project, a learning technologies enrichment program, and a program to help departments fund innovative ways to enhance undergraduate research.

A university-wide community has been created and strengthened through teaching. In the annual evaluations mentioned earlier, the third highest impact reported was on the Scholars' comfort as members of the Miami University community (the mean over the years is 8.1 on the 10 - point scale). 
Former participants now serve as mentors and seminar leaders; two are now department chairs.

Program graduates have contributed to greater coherence of learning across disciplines. In 1990, the Miami Plan, a new general education program broadening cross-disciplinary curriculum and collaboration, was approved by the University Senate after four years of planning and discussion. Many former teaching scholars and mentors participated in its development.

Undergraduate student learning has been enhanced in many ways. Students learn more from enthusiastic, interested teachers (Weimer, 1990). The Teaching Scholars become such teachers. Some participants also indicated in the open-ended part of their final reports that their student evaluation ratings had increased an entire point on a four-point scale. The participants reported that another high impact the program had was on their total effectiveness as a teacher; the mean over the years is 7.8 on the 10-point scale.

Miami's tenure study, comparing Miami junior faculty who participated in the Program with those who chose not to, found a significant association between Program participation and a positive tenure decision (Cox, in press).

The Teaching Scholars Program has been recognized nationally as one of the best junior faculty development programs. Austin (1990), in a review of 30 former Lilly Teaching Fellows Programs, 19741988, recognized the Program at Miami as one of four current, exemplary, continuing programs in the country.

Over the past 16 years, the Teaching Scholars Program has had a tremendous impact on the Miami community. One hundred forty-nine junior faculty and 118 mentors have participated. The success of the Program has spawned interest and resources to create the wide variety of related teaching programs mentioned above. The budget for faculty teaching improvement has increased tenfold during this period. Based upon the success of the Program's mentoring element, the President endorsed and encouraged a senior faculty mentoring program for new faculty in all departments. Former Program participants have been active in establishing a new university-wide general education curriculum and a campus-wide teaching portfolio project. Senior faculty have admired the Teaching Scholars Program to the extent that they 
have lobbied for, designed, and now implemented a similar program, the Senior Faculty Program for Teaching Excellence. More undergraduates are involved in research, working in small seminars and one-to-one with professors. There is more collaboration across disciplines and campuses than ever before.

How has Miami found such substantial support and maintained enthusiasm for the Teaching Scholars Program for so many years? The strategies and leadership mentioned above have fostered enthusiasm in the junior faculty participants, who have convinced students, colleagues, chairs, deans, and provosts that the Program works. Junior faculty are hungry for colleagueship across disciplines, and they now arrive at Miami with an interest in teaching. Finally, leading the Program is an exciting and rewarding experience for the Director.

Through a faculty development program for junior faculty, the university has reclaimed teaching excellence. The culture did change; the ripple effect occurred. A university-wide community has been built around teaching.

\section{References}

Alessio, H. M. (1991). Use of educational games for difficult subject material. Journal on Excellence in College Teaching, 2, 71-76.

Angelo, T. A., \& Cross, K. P. (1993). Classroom assessment techniques: A handbook for college teachers (2nd ed.). San Francisco: Jossey-Bass.

Austin, A. E. (1990). To leave an indelible mark: Encouraging good teaching in research universities through faculty development. A study of the Lilly Endowment's teaching fellows program 1974-1988. Nashville, TN: Vanderbilt University, Peabody College.

Baxter Magolda, M. B. (1992). Knowing and reasoning in college: Gender-related patterns in students' intellectual development. San Francisco: Jossey-Bass.

Belenky, M. B., Clinchy, B. M., Goldberger, N. R., \& Tarule, J. M. (1986). Women's ways of knowing: The development of self, voice, and mind. New York: Basic Books.

Boice, R. (1992). The new faculty member: Supporting and fostering professional development. San Francisco: Jossey-Bass.

Boyer, E. L. (1990). Scholarship reconsidered: Priorities of the professoriate. Princeton, NJ: The Carnegie Foundation for the Advancement of Teaching.

Bishop-Clark, C., \& Lynch, J. (1992). The mixed-age classroom. College Teaching, 40(3), 114-117.

Cottell, P. G., Jr., \& Millis, B. J. (1994). Instructor's resource guide. [For] R. W. Ingram, Financial accounting: Information for decisions. Cincinnati: South-Western. 
Cox, M. D. (in press). The development of new and junior faculty. In W. A. Wright (Ed.), Successful faculty development: Strategies to improve university teaching. Bolton, MA: Anker.

Flannery, B., \& Vanterpool, M. (1990). A model for infusing cultural diversity concepts across the curriculum. In L. Hilsen (Ed.), To improve the academy: Resources for student, faculty, \& institutional development (pp. 159-175). Stillwater, OK: Professional \& Organizational Development Network in Higher Education/New Forums Press.

Lowman, J. (1984). Mastering the techniques of teaching. San Francisco: Jossey-Bass.

McKeachie, W. J. (1994). Teaching tips: Strategies, research, and theory for college and university teachers (9th ed.). Lexington, MA: D. C. Heath.

Millis, B. J. (1991). Fulfilling the promise of the "seven principles" through cooperative learning: An action agenda for the university classroom. Journal on Excellence in College Teaching, 2, 139-144.

Sorcinelli, M. D., \& Austin, A. E. (Eds.). (1992). New directions for teaching and learning: No. 50. Developing new and junior faculty. San Francisco: Jossey-Bass.

Weimer, M. (1990). Improving college teaching: Strategies for developing instructional effectiveness. San Francisco: Jossey-Bass. 


\title{
Appendix
}

\author{
MIAMI UNIVERSITY \\ TEACHING SCHOLARS PROGRAM \\ END-OF-YEAR FINAL EVALUATION \\ 1993-94
}

Your Name:

Please complete and return to Milt Cox by August 1. This report and an evaluation or summary of all the reports may be reviewed by the Committee for the Improvement of Instruction, University Senate, and the Provost as they plan for the future. Thank you.

1. How would you rate the impact on you of each of the following elements of the Teaching Scholars Program? Circle the number on the scale below which reflects your judgment. '1\% would indicate a very weak impact and ' $10 \%$ a very strong impact. Also, if you have a comment to make about any of these aspects of the program, use the space provided.

A. The Mentor relationship
23
45
$\begin{array}{lll}6 & 7 & 8\end{array}$
$9 \quad 10$

B. Observation of Mentors or others classes

$\begin{array}{llllllllll}1 & 2 & 3 & 4 & 5 & 6 & 7 & 8 & 9 & 10\end{array}$

C. The retreats and national conferences

$\begin{array}{llllllllll}1 & 2 & 3 & 4 & 5 & 6 & 7 & 8 & 9 & 10\end{array}$

D. Seminars

$\begin{array}{llllllllll}1 & 2 & 3 & 4 & 5 & 6 & 7 & 8 & 9 & 10\end{array}$ 
E. The teaching project

$\begin{array}{llllllllll}1 & 2 & 3 & 4 & 5 & 6 & 7 & 8 & 9 & 10\end{array}$

F. Release time

$\begin{array}{llllllllll}1 & 2 & 3 & 4 & 5 & 6 & 7 & 8 & 9 & 10\end{array}$

G. The colleagueship and learning from the other Teaching Scholars

$\begin{array}{llllllllll}1 & 2 & 3 & 4 & 5 & 6 & 7 & 8 & 9 & 10\end{array}$

2. In a similar manner, estimate the impact of the Teaching Scholars Program as a totality on each of the following, using ' $1 \%$ as weak impact and " 10 " as strong impact.

A. Your technical skill as a teacher

$\begin{array}{llllllllll}1 & 2 & 3 & 4 & 5 & 6 & 7 & 8 & 9 & 10\end{array}$

B. Your total effectiveness as a teacher

$\begin{array}{llllllllll}1 & 2 & 3 & 4 & 5 & 6 & 7 & 8 & 9 & 10\end{array}$

C. Your interest in the teaching process

$\begin{array}{llllllllll}1 & 2 & 3 & 4 & 5 & 6 & 7 & 8 & 9 & 10\end{array}$

D. Your research and scholarly interest with respect to your discipline

$\begin{array}{llllllllll}1 & 2 & 3 & 4 & 5 & 6 & 7 & 8 & 9 & 10\end{array}$

E. Your view of teaching as an intellectual pursuit

$\begin{array}{llllllllll}1 & 2 & 3 & 4 & 5 & 6 & 7 & 8 & 9 & 10\end{array}$ 
F. Your understanding of and interest with respect to the scholarship of teaching

$\begin{array}{llllllllll}1 & 2 & 3 & 4 & 5 & 6 & 7 & 8 & 9 & 10\end{array}$

G. Your awareness of ways to integrate the teaching/research experience

$\begin{array}{llllllllll}1 & 2 & 3 & 4 & 5 & 6 & 7 & 8 & 9 & 10\end{array}$

H. Your comfort as a member of the Miami University community

$\begin{array}{llllllllll}1 & 2 & 3 & 4 & 5 & 6 & 7 & 8 & 9 & 10\end{array}$

I. Your understanding of the role of a faculty member at Miami University

$\begin{array}{llllllllll}1 & 2 & 3 & 4 & 5 & 6 & 7 & 8 & 9 & 10\end{array}$

3. If not covered by the above questions, what have you valued most from your participation in the Teaching Scholars Program?

4. Describe how your teaching and your perception of yourself as a teacher have changed (if they have) as a result of your involvement in the Teaching Scholars Program. Please be as specific as possible.

5. What aspect(s) of the program could be changed to make it more valuable for future Teaching Scholars?

6. Additional comments 


\section{MIAMI UNIVERSITY \\ TEACHING SCHOLARS PROGRAM \\ FINAL REPORT \\ Due September 1}

Please format your report with the same heading as above. List your name, title and department directly below this heading. These reports will be bound and available for reading by the Committee on the Improvement of Instruction, the Provost, and faculty interested in the program. Structure your report using the following outline or make sure all the requested information is included. This report should be no more than 4 pages in length; you may attach appendices.

\section{Goals and Objectives for the Year}

These may have changed as the year progressed, so you may wish to discuss the transition. You may wish to reread your application, Initial Learning Plan and Mid-Year Progress Report. Briefly summarize in what ways and with what success you have (or have not) met your goals and objectives.

\section{Teaching/Learning Activities}

Mention how your teaching/learning activities have been related to your goals and objectives.

\section{A. The Teaching Project(s)}

Some of you have indicated that your project may lead to or has already led to something tangible, such as publications or presentations at conferences, etc. Be sure to mention these, and attach a copy or rough draft if that is the status at this point. If a publication, workbook, etc., comes to fruition later, please send it to the Director. Another example: One year a participant had his students write project papers as part of a new approach to his teaching a certain course; he included a notebook of the finished copies of their work. Some of your teaching projects, or some parts of them, did not result in a tangible outcome, and such a project can be as valuable. For 
example, if your project involved personal growth, give the details, the outcome and your evaluation of the method tried. In some cases your projects are not completely finished; for example, certain techniques are still to be tried or evaluated in a course during the upcoming year. Include your plans for this.

If your Mentor, readings or other parts of the program contributed to your project, indicate that, too.

\section{B. Interaction With Your Mentor(s)}

Mention in what ways and how often this occurred. What has this contributed to your experience? Do you plan to continue informally? How could this aspect of the program have been better?

\section{The Scholarship of Teaching}

What is your understanding of this concept? In what ways have you been involved in the scholarship of teaching? Do you plan to continue? What is the climate in your department regarding the scholarship of teaching? If the climate is a chilly one, should it be changed, and if so, how?

\section{Use of Funds}

How have you used all or part of your $\$ 125$ ? What effect has this or will this have on your project and, in general, on your teaching?

\section{E. Other Activities}

\section{Summary and Future}

This should be a brief summary of your year as a Teaching Scholar and its impact on you and your teaching. Here you may wish to synthesize items 3 and 4 of the Mid-Year Progress Report and the End-of-Year Evaluation. Finally, what plans do you have for the future with respect to teaching? 